\title{
Filoarqueologia literária
}

\author{
Las Otras (Antología mínima del \\ Silencio).
}

BOLAÑOS, Aimée.

Madrid: Ediciones Torremozas, 2004. $62 \mathrm{p}$.

Aimée G. Bolaños nasceu em Cuba e desde 1997 reside no Brasil, atuando como docente na Fundação Universidade Federal do Rio Grande. Dedica-se às letras como ensaísta e escritora, tendo publicado em diversos países. Doutora em Ciências Filosóficas pela Universidade de Rostock Alemanha, integra a União de Escritores e Artistas de Cuba. Seu mais recente livro, Las Otras (Antología mínima del Silencio), publicado na Espanha, apresenta a literatura de autoria feminina observada por um prisma inovador. São 24 escritoras, filhas de diversos países, dentre outros Cuba, Brasil, Itália, Japão, Alemanha, China, Portugal, de várias épocas, mas unidas pelo fio condutor comum de serem mulheres $e$ escritoras. A autora constrói uma antologia com poemas apócrifos, o que surpreende e torna a leitura instigante. Há poemas atribuídos a Jeanne Duval e Artemísia Gentileschi, por exemplo, nomes já conhecidos, porém não como poetisas, assim como poema de autoria da brasileira Carla Teresinha de Souza e mesmo da própria Aimée Bolaños. Elas representam um universo de escritoras com características próprias e que se expressam através dos versos. As escritoras são apresentadas cronologicamente, desde Cleis, nascida no século VI a.C., até Alina César, em 1953.

Um livro assim estruturado pede uma introdução, com luzes que possam orientar a leitura, e Las Otras (Antología mínima del Silencio), segundo a autora - "así com mayúsculas para que alcanzara alguna notoriedad" -, oferece "Palabras al lector", que se constitui uma criação literária à parte, com explicações sobre as mulheres às quais a escritora fez referência, com um veio humorístico e fina ironia entremeando esses esclarecimentos, como por exemplo ao justificar a necessidade de um prólogo: "[...] porque mientras más intento esconderme de modo más impúdico aprovecho el privilegio del uso de la palabra como prologista, antóloga y autora - práctica entre bizarra y narcisista nada rara en la crítica literaria [...]" (p. 13). A autora destaca o valor do resgate de textos de autoria feminina, que por razões várias - boa parte delas sustentadas a partir de uma postura retrógrada e preconceituosa de parte da sociedade acabaram se perdendo e em função disso muitas escritoras, em especial as nascidas no século XIX, mantiveram-se praticamente esquecidas, à margem da tradição literária. Assim, Aimée destaca que sua antologia colabora para estremecer "no importa cuán levemente" o cânone, reflexo da sociedade à qual serve como modelo. Nesse trabalho de arqueologia literária, a autora destaca o prazer próprio das descobertas, de poder trazer novamente a publico textos reveladores da vivência não somente daquelas que escreveram, mas também de outras as quais elas representam. Logo, as diferentes escritoras expressaram os anseios e o desejo de registrar seus pensamentos através da arte literária e sempre haverá uma identificação, uma espécie de olhar especular por parte das que as lerem.

O prefácio apresenta uma contextualização das poetisas, com informações a respeito de sua origem. Dentre elas encontram-se Cleis e Athil, discípulas de Safo, Angélica Stanza, representante das cortesãs ilustradas, e as que, como Jeanne Duval, tiveram existência à sombra de escritores consagrados. Além dessas, são citadas as religiosas, escritoras ligadas à vida conventual e aquelas que deixaram a pátria e passaram a viver em outros países, assumindo a identidade do "outro". Assim, várias mulheres integram a antologia criada por Aimée, cada qual colaborando com uma escrita própria, expressão de uma vivência singular, no entanto com muito em comum, mostrando que, apesar das diferenças, cada uma, a seu modo, contribui para uma escrita literária feminina.

Uma obra assim se diferencia das antologias 'tradicionais' e lhe confere um status próprio. Mas há outros relevantes aspectos a serem destacados, como a reflexão acerca da autoria feminina e os temas abordados. Se hoje não se pode afirmar que haja eqüidade entre os sexos quando o assunto é literatura, ainda menos em séculos anteriores. Assim, é necessário reunir a escrita feminina, esparsa no tempo e no espaço, 
para que se possa compreendê-la melhor. Outras antologias de escritoras fizeram percurso semelhante e geralmente os temas abordados expressam, ao menos em relação às escritoras, a preocupação com o lugar ocupado pela mulher e a representatividade de sua atuação. As mulheres sempre se ocuparam com a escrita, valendo-se do registro epistolar, diários, memórias, poemas, romances e ensaios. E através dos vários gêneros literários revelavam anseios e perspectivas. São esses registros que viabilizam uma tradição literária feminina, ainda que frágil, nos dias de hoje.

O fato de Aimée Bolaños ter elaborado a antologia revela a preocupação em discutir a autoria feminina, e se essa discussão ainda se estende no século XXI é porque a participação das mulheres na literatura não está bem compreendida, ou aceita. Isso é de certa forma expresso pelo título da obra, Las Otras (Antología mínima del Silencio). A palavra "outras" remete a O segundo sexo, ' de Simone de Beauvoir, no qual a escritora francesa aborda de forma precursora as relações de gênero, apontando a representação masculina como o "um" - o Sujeito, - Absoluto - e a mulher como o "outro". Há a referência ao silêncio feminino, histórico, e que muitas vezes se aproxima da omissão, ou, talvez pior, uma eloqüência vazia, afinada com um discurso que não nos pertence, o que não legitima a inserção na literatura. As escritoras da antologia distinguem-se nesse aspecto, pois procuram posicionar-se como protagonistas de suas atitudes, exprimindo emoções e adotando posturas como a preocupação com a literatura e a expressão de desejos sensuais. Um dos poemas, conferido a Inês Maria Sepúlveda, apresenta versos que conotam o valor de se manter as esperanças, para não esmorecer: "Los ojos están fijos / en un punto ciego / donde comienza / el otro sueño" (p. 45). São as perspectivas que propiciam $\circ$ recomeço; o fato de acreditar adquire um sentido para a existência.

Os poemas que compõem a antologia revelam um panorama literário feminino que agrega mulheres com expectativas em relação à palavra, não a verbalização frívola, mas aquela densa de significação. Esse acesso às letras se faz através de uma tradição, a qual dificilmente se efetiva com as lacunas e omissões observadas na escrita das mulheres. Assim, quando no poema atribuído a Angélica Stanza encontramos versos como "El estilo é lluvia fina / que te fecunda, Palabra" (p. 24), percebemos que não se trata somente de escrever, mas escrever com convicção e arte. Para que isso se concretize é necessário estabelecer uma tradição literária feminina, que possa ser passada através dos tempos, analisada, criticada, reelaborada, mas que exista e não seja uma espécie de palimpsesto, sob pena de se adiar uma integração efetiva das mulheres à literatura.

Os atos de transgressão podem ser expressos de várias formas: o fato de escrever, em épocas nas quais poucas mulheres eram alfabetizadas, representava em si mesmo uma postura diferenciada; tornar-se escritora de maneira consciente e assumir os riscos que isso poderia significar indica um avanço. Além disso, há ainda a questão do gênero literário adotado. Em Las Otras a autora reúne poemas, os quais foram como que a porta de entrada para as mulheres no campo da literatura. O senso comum era considerar que a alma feminina se moldava aos versos, pela sensibilidade e singeleza da forma, com um eu-lírico que se derramava em sentimentos. Para completar 0 cenário, a escolha de um pseudônimo, com o objetivo de se proteger das críticas, um prólogo pretensamente calcado na modéstia e de preferência com a apresentação do livro feita por um escritor, 'avalizando' o escrito e, geralmente, enaltecendo as tais qualidades relacionadas à meiguice e à simplicidade. No entanto, muitas escritoras, mesmo em épocas distantes, não se conformavam aos estereótipos, os quais corroboravam uma escrita feminina estigmatizada. Aimée também transgrediu, pois os poemas da antologia se distanciam desse ideal dos versos fúteis e apresentam escritoras com uma mirada vigorosa e versos intensos. Enfim, as mulheres falam, livrando-se do destino silencioso por tanto tempo a elas reservado e ao qual nos remete o título do livro.

Muitas escreveram com o aval de Deus, ou seja, seus textos refletem uma intensa religiosidade que guia os versos e colabora para respaldar sua escrita. No Brasil houve, por exemplo, Maria Cândida de Jesus Camargo, que adotou um eu-poético bem próximo dos ideais cristãos, de fraternidade e humildade, e Hilda Leite Guimarães, ${ }^{2}$ a qual adotou o pseudônimo de Ancilla Domini e escreveu contos de cunho moral para a infância e a juventude. A escrita das mulheres ligadas à vida religiosa é apresentada na antologia, dentre outras, por Sor Clara de la Gracia, que extravasa de forma profana/religiosa: "Me gustan los ángeles / violentos. / Los ángeles furiosos, / caídos. / Yacen fervientes / devotamente / em mi cuerpo. / Son mi único lastre" (p. 28). Os versos anteriores exemplificam o distanciamento crítico adotado 
na antologia e expõem a maneira diversa através da qual as mulheres, mesmo aquelas ligadas à religião, seriam capazes de se expressar em seus poemas.

Algumas escritoras da antologia se ligam em função da diáspora. Refletem em seus poemas a saudade das origens e aquilo que Edward Said dizia ser uma espécie de estado constante de melancolia. Nesse caso, a literatura assume também a forma de um lenitivo ao sofrimento das que estão longe de sua terra, representadas por Calixta Rey em Quasisoneto: "Huérfanos de la tierra amada / sin el signo y la mandala. / De la infinita luz refractada, / apenas la sombra del ala" (p. 44) - e por Aimée Bolaños: "Me hago de retazos / de innumerables trajes / vestida / ya fu hija / de una isla / mediterránea / y del continente / reclusa y anarquista / lujuriosamente mística todas las letras / me habitan" (p. 51). A distância da pátria enseja a produção literária de muitas mulheres, mesmo as que não se consideram escritoras e que escrevem como forma de apaziguar a saudade, muitas vezes através de reminiscências. $\mathrm{O}$ exílio voluntário, por motivos financeiros especialmente, levou muitas pessoas a adotarem um outro país para viver. No entanto, quando se trata de um exílio forçado em virtude de conflitos políticos e a distância da terra nata é obrigatória, a literatura assume uma função ainda mas importante, pois pode se converter em um meio de denúncia e colaborar decisivamente para o estabelecimento de uma nova realidade.

Ao conceber seu livro como uma antologia de vozes silenciadas, Aimée Bolaños compõe um painel ilustrado por mulheres representativas a partir de vários prismas diferentes, encaminhando um percurso literário novo, do ponto de vista formal, desafiador e verdadeiro. A autora demonstra que muitas outras mulheres que escreveram ainda podem estar esquecidas aguardando um trabalho "filo-arqueológico" que as restitua ao campo literário - podem se chamar Joana, Luísa, terem nascido no Chile ou no Japão. Talvez nos surpreendam, talvez corroborem com o preconceito em relação à escrita feminina. Mas escreveram, desafiando o cânone ou tentando a ele se afinar, desde os tempos mais remotos até os dias de hoje, e a crítica literária feminista enseja um olhar renovador a esses textos, a partir de outros paradigmas, que possibilitam compreender melhor a participação feminina nas letras. Desvelar esses escritos pode permitir encontrar escritoras como Aika Kiu, do Japão, que contribuiu com o gênero haiku, tradicionalmente relacionado aos homens em seu tempo; como a brasileira Gertrudes da Veiga e a proximidade com a cultura regional, horizonte até onde seus olhos alcançavam; como Alina César, de Cuba, e a expressão de saudades da terra natal.

Se em um tempo qualquer houve escritoras como essas e por motivos que intuímos elas foram olvidadas da história literária, contemporaneamente podem ser reavaliadas e seus textos apreciados. A postura do público leitor possibilita fazer com que a história seja reescrita, e uma escritora que teve seu livro 'indexado' pela preservação da moral e bons costumes de uma determinada sociedade, por exemplo, atualmente pode ser considerada uma vanguardista, incompreendida por sua época. Las Otras (Antología mínima del Silencio) é um livro para se refletir acerca da literatura de autoria feminina e não são apenas as letras maiúsculas do título que lhe conferem notoriedade.

\section{Notas}

1 BEAUVOIR, 2000.

${ }^{2}$ Maria Cândida de Jesus Camargo (1868-1949) e Hilda de Almeida Leite Guimarães (pseudônimo: Ancilla Domini) (1877-1916). Ver estudo sobre as escritoras em Zahidé Lupinacci MUZART, 2004

\section{Referências bibliográficas}

BEAUVOIR, Simone. O segundo sexo. Trad. Sérgio Milliet. Rio de Janeiro: Nova Fronteira, 2000. v. 1.

MUZART, Zahidé Lupinacci (Org.). Escritoras brasileiras do século XIX. Florianópolis: Editora Mulheres; Santa Cruz do Sul: EDUNISC, 2004. v. 2.

Rosana Cássia Kamita Universidade Estadual de Londrina 